\title{
A unique morphological feature commonly associated with Bacillus thuringiensis serovar yunnanensis isolates: An electron microscopic observation
}

\author{
Michio OHвA, ${ }^{1, *}$ Minoru MaedA, ${ }^{2}$ Akira OHguShI, ${ }^{1}$ Dong-Hyun LEE $^{1}$ and Eiichi MizukI ${ }^{3}$ \\ ${ }^{1}$ Graduate School of Agriculture, Kyushu University; Fukuoka 812-8581, Japan \\ ${ }^{2}$ Kyushu Medical Co. Ltd.; Kokurakita-ku, Kitakyushu, Fukuoka 803-0814, Japan \\ ${ }^{3}$ Biotechnology and Food Research Institute, Fukuoka Industrial Technology Center; Kurume, Fukuoka 839-0816, Japan
}

(Received 29 January 2003; Accepted 2 April 2003)

\begin{abstract}
When examined with a phase-contrast microscope, all of the 15 Bacillus thuringiensis serovar yunnanensis (H20ab) strains, the reference type strain and the 14 Japanese isolates, produced large rhomboidal inclusions in spore-lacking cells but not in spore-forming cells. No envelopes were associated with inclusions. Inclusion matrix consisted of electron-dense homogeneous substances. The frequency of inclusion-forming cells was $<1 \%$ of the cell population in each strain. Also, phase-dark spherical bodies, much smaller than rhomboidal inclusions, were often associated with cells in sporulating cultures. Electron microscopic studies with the four selected yunnanensis strains revealed that: (1) the majority of cells produced spores but not crystalline inclusions, (2) formation of crystalline inclusions was limited to the spore-lacking cells, and (3) electron-dense round bodies, much smaller than rhomboidal crystalline inclusions and putatively assigned to poly- $\beta$-hydroxybutyrate inclusions, were often observed in both spore-forming cells and inclusion-forming asporogenous cells. The overall results strongly suggest that the formation of crystalline inclusions in asporogenous cells is an $\mathrm{H}$ serotype-specific phenotype characteristic of the B. thuringiensis serovar yunnanensis.
\end{abstract}

Key words: Bacillus thuringiensis serovar yunnnensis; H-serotype 20ab; crystalline inclusion; inclusion-forming sporeless cell

\section{INTRODUCTION}

Bacillus thuringiensis is a Gram-positive sporeforming bacterium that is characterized by the formation of proteinaceous parasporal inclusions in sporangia. The parasporal inclusions often exhibit insecticidal and nematocidal activities (Glare and O'Callaghan, 2000). This makes B. thuringiensis an ecologically sound biological agent for control of agriculturally and medically important insect pests. Moreover, recent investigators have reported the occurrence of other biological activities in parasporal inclusion proteins of this organism (Akao et al., 1999; Mizuki et al., 1999b, 2000; Kondo et al., 2002).

Currently, 69 flagellar $(\mathrm{H})$ antigenic serotypes are involved in the infraspecific classification scheme of B. thuringiensis (Lecadet et al., 1999). $B$. thuringiensis serovar yunnanensis (flagellar serotype H20) was established by Yu et al. (1984) on the basis of a Chinese strain recovered from a larval cadaver of a noctuid lepidopteran, Spodoptera litura (Wang et al., 1979). The H-serotype 20 is now divided, by the presence of three $\mathrm{H}$ antigenic subfactors (20a, 20b, and 20c), into two subserotypes, H20ab (serovar yunnanensis) and H20ac (serovar pondicheriensis) (Lecadet et al., 1999).

The occurrence of $B$. thuringiensis belonging to the serovar yunnanensis in Japan was first reported by Ohba and Aizawa (1986a) with special reference to an interesting observation that the type strain and a Japanese isolate of this serovar produced huge crystalline inclusions only in asporogenous cells. Subsequent intensive efforts to screen B. thuringiensis, effective for microbial control of insect pests, from natural environments of Japan have occasionally provided the organisms belonging to the serovar yunnanensis (Ohba, 1996; Mizuki et al., 1999a; Ohba et al., 2000, 2002; M. Ohba, unpublished observations). This paper reports an unusual phenotypic character, the lack of formation of crystalline inclusions in sporogenous cells, com-

* To whom correspondence should be addressed at: E-mail: ohba@brs.kyushu-u.ac.jp 
Table 1. Bacillus thuringiensis serovar yunnanensis isolates used in this study

\begin{tabular}{|c|c|c|c|}
\hline Isolate $^{a}$ & Locality & Source & Reference \\
\hline Type strain & Yunnan, China & Spodoptera litura (cadaver) & Wang et al., 1979 \\
\hline $116-72$ & Tochigi & Soil & Ohba and Aizawa, 1986a \\
\hline $91-\mathrm{KS}-12-5^{\dagger}$ & Kagoshima (Amami-oshima) & Soil & M. Ohba, unpubl. \\
\hline $91-\mathrm{KS}-12-8^{\dagger}$ & Kagoshima (Amami-oshima) & Soil & M. Ohba, unpubl. \\
\hline $93-Y-28-20$ & Yamaguchi & Soil & M. Ohba, unpubl. \\
\hline $94-\mathrm{F}(\mathrm{M}) 6-30-5$ & Fukuoka & Phylloplane & Ohba, 1996 \\
\hline $94-F(M) 8-20-18$ & Fukuoka & Phylloplane & Ohba, 1996 \\
\hline $97-\mathrm{OK}-13-7^{\ddagger}$ & Okinawa (Iriomote-jima) & Soil & Ohba et al., 2000 \\
\hline $97-O K-13-13^{\ddagger}$ & Okinawa (Iriomote-jima) & Soil & Ohba et al., 2000 \\
\hline $97-O K-13-23^{\ddagger}$ & Okinawa (Iriomote-jima) & Soil & Ohba et al., 2000 \\
\hline 97-OK-240-13 & Okinawa (Ishigaki-jima) & Soil & Ohba et al., 2000 \\
\hline $01-\mathrm{KDT}-118-10^{\S}$ & Okinawa (Kitadaito-jima) & Soil & Ohba et al., 2002 \\
\hline $01-\mathrm{KDT}-118-15^{\S}$ & Okinawa (Kitadaito-jima) & Soil & Ohba et al., 2002 \\
\hline 01-KDT-120-1 & Okinawa (Kitadaito-jima) & Soil & Ohba et al., 2002 \\
\hline B52 & Fukuoka & Phylloplane & Mizuki et al., 1999a \\
\hline
\end{tabular}

${ }^{\mathrm{a}}$ Isolates with the same letter were from a single source.

monly retained in these Japanese yunnanensis isolates.

\section{MATERIALS AND METHODS}

Organisms and culture conditions. Fifteen $B$. thuringiensis strains used in the present study are listed in Table 1. Of these, 14 strains were derived from natural environments of Japan. The type strain of serovar yunnanensis was obtained from Dr. W. Wang, Kunming, China. The Japanese strains had been previously identified to the serovar yunnanensis ( $\mathrm{H} 20 \mathrm{ab}$ ) by using $\mathrm{H}$ antisera specific for $20 \mathrm{~b}$ and $20 \mathrm{c}$ subfactors, respectively.

B. thuringiensis strains were grown at $28^{\circ} \mathrm{C}$ on nutrient agar, $\mathrm{pH} 7.8$, consisting of meat extract $(10 \mathrm{~g})$, polypeptone $(10 \mathrm{~g}), \mathrm{NaCl}(2 \mathrm{~g})$, agar $(20 \mathrm{~g})$, and distilled water $(1,000 \mathrm{ml})$.

Morphological observations. Three-day-old cultures of the 15 yunnanensis strains were examined for morphological features of the sporulating cells under a phase-contrast microscope. Four selected strains were further examined by the transmission electron microscopy (EM). For EM, threeday-old bacterial cultures were prefixed by $1 \%$ glutaraldehyde in phosphate-buffered saline (PBS), $\mathrm{pH} 7.2$, at $25^{\circ} \mathrm{C}$ for $1 \mathrm{~h}$, and postfixed by $1 \% \mathrm{OsO}_{4}$ in PBS at $25^{\circ} \mathrm{C}$ for $1 \mathrm{~h}$. The fixed samples were dehydrated in an ethanol-propylene oxide series and embedded in Epon 812 resin mixture. Ultrathin sections were made on a Reichert Ultracut micro- tome, stained with uranyl acetate and lead citrate. Sections were examined with a Hitachi 7200 electron microscope.

\section{RESULTS}

When observed with a phase-contrast microscope, there was no significant difference between the type strain of yunnanensis and 14 Japanese isolates in morphological features of vegetative cells, sporangia, and spores. All 15 strains formed huge crystalline inclusions in spore-lacking cells but not in spore-producing cells. Inclusion-forming cells accounted for $<1 \%$ of cell populations in each strain. Figures 1-4 show phase-contrast photographs of the four selected strains: the type strain of yunnanensis and the three Japanese strains, B52, 97OK-13-7, and 01-KDT-118-10. Inclusions were roughly rhomboidal in shape with sizes $(3-7 \mu \mathrm{m}$ long) much greater than the spores that were formed in inclusion-lacking cells. Also, much smaller phase-dark spherical bodies were evident in cells.

Figures 5-12 show electron micrographs of the cells in sporulating cultures of the four selected yunnanensis strains. Sporulating cultures of these strains consisted of two cell types in terms of the formation of spores and crystalline inclusions. In each strain, the majority of cells produced spores but not crystalline inclusions. Formation of crystalline inclusions was strictly limited to the spore- 

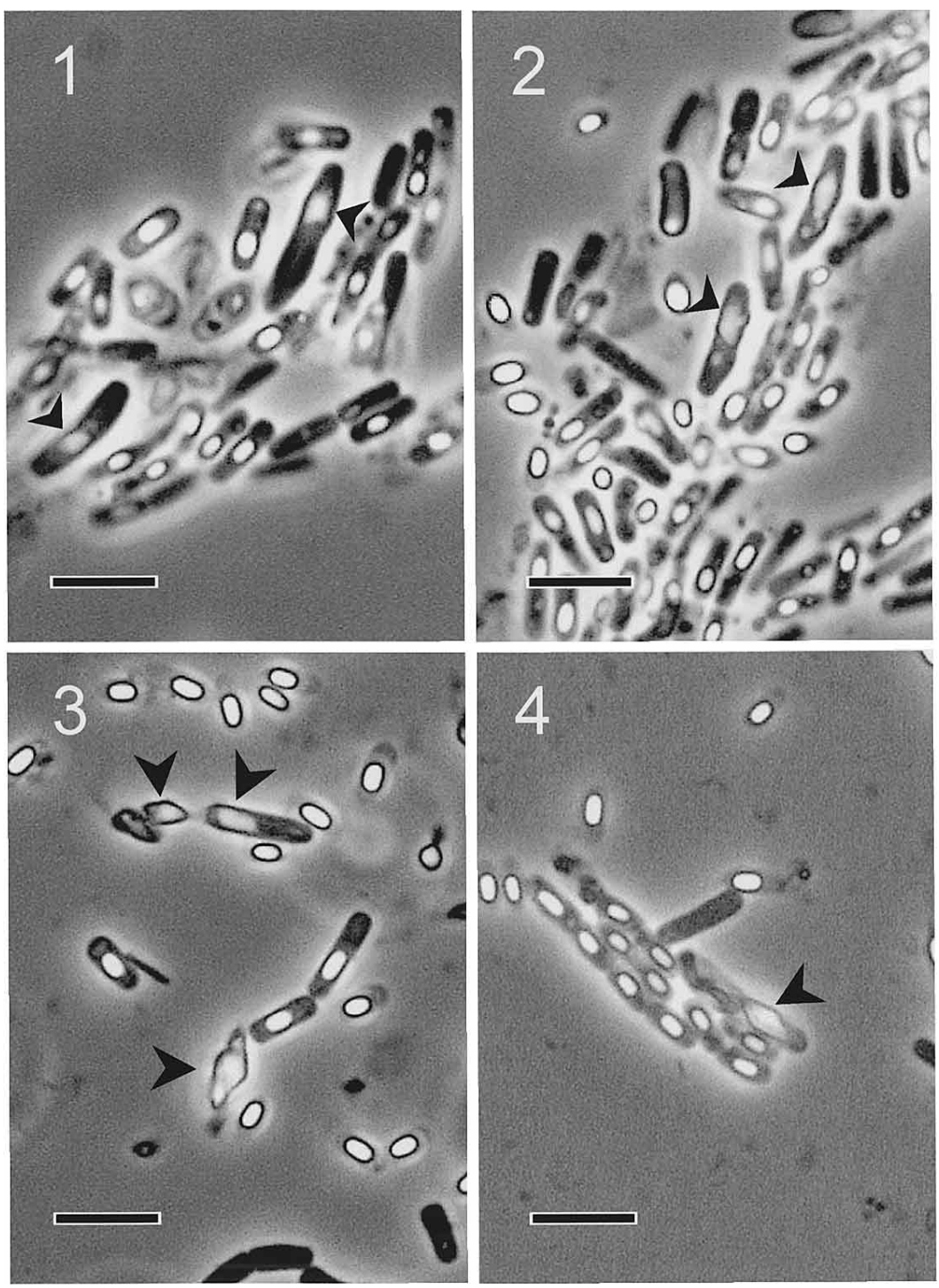

Figs. 1-4. Phase contrast photographs of sporulating cultures of Bacillus thuringiensis serovar yunnanensis (H20ab) strains. Arrowheads indicate rhomboidal crystalline inclusions formed in spore-lacking cells. Bar $=10 \mu \mathrm{m}$. (1) The type strain of serovar yunnanensis. (2) The soil isolate 01-KDT-118-10. (3) The soil isolate 97-OK-13-7. (4) The phylloplane isolate B52.

lacking cells, accounting for $<1 \%$ of the cell population. Usually, multiple inclusions were formed in single asporogenous cells: in most cells, the largest inclusion was roughly rhomboidal in outline, and the smaller crystalline inclusions were varied not only in size but also in shape. Occasionally, narrow and considerably elongated inclusions coexisted with rhomboidal ones (Fig. 12). The inclusions were not enveloped, consisting of an electron-dense homogeneous matrix. As shown in Fig. 6, the smaller inclusions were occasionally embedded into the larger ones.

The four selected yunnanensis strains also produced various-sized round bodies $(0.1-0.5 \mu \mathrm{m}$ in diameter) different from the above rhomboidal crystalline inclusions (Figs. 5-12). Occasionally, single cells contained multiple round bodies. These bodies were much more smaller than the crystalline inclusions and spores, consisting of highly electron-dense substances. They were observed not only in spore-containing cells but in rhomboidal inclusion-producing asporogenous cells.

\section{DISCUSSION}

It has been well established that the ordinary $B$. 

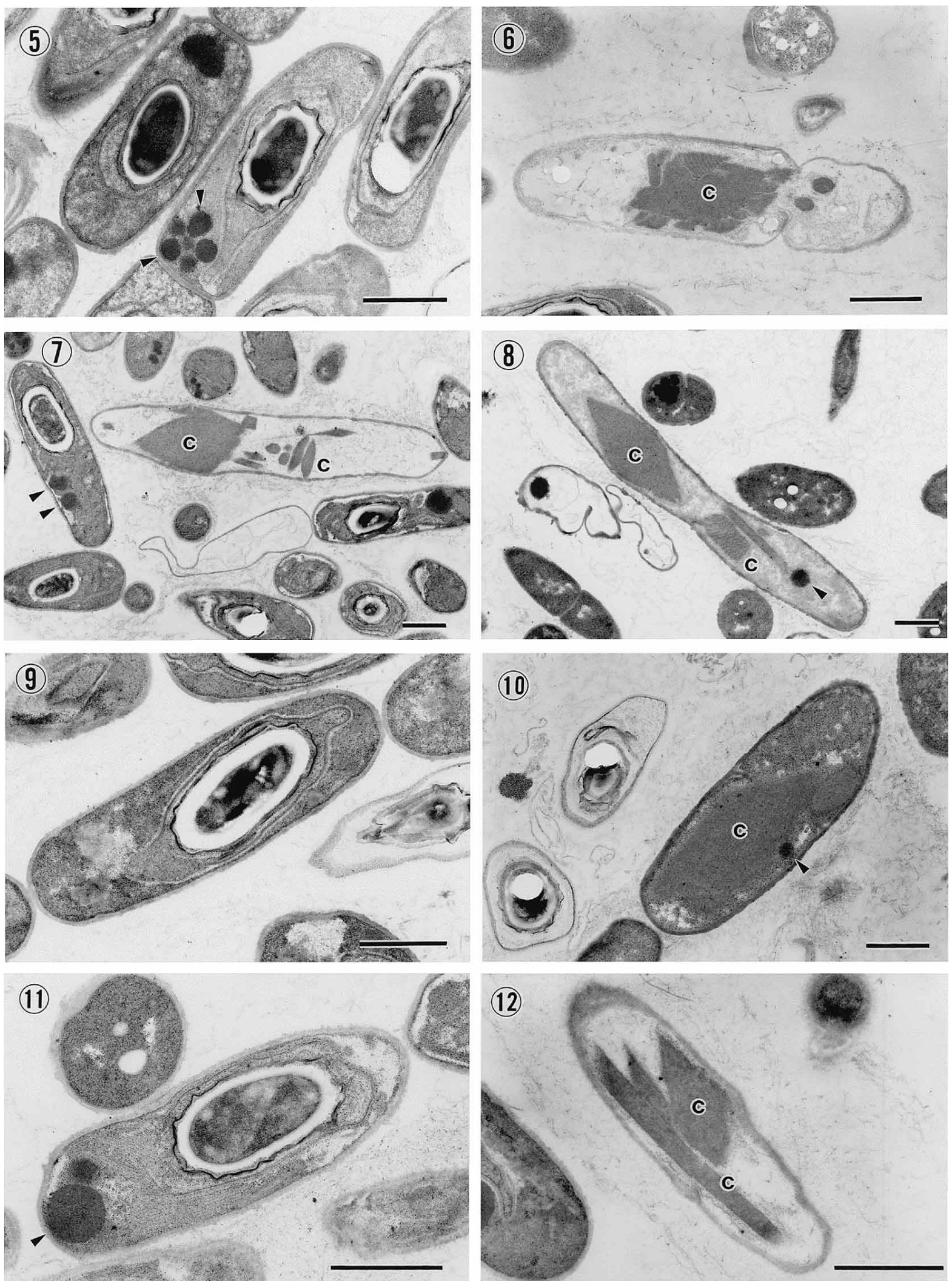

Figs. 5-12. Electron micrographs of acrystalliferous sporangia and crystalline inclusion-forming asporogenous cells in Bacillus thuringiensis serovar yunnanensis (H20ab) strains. (C) Crystalline inclusions. Arrowheads indicate putative poly- $\beta$-hydroxybutyrate bodies. Bar $=1 \mu \mathrm{m}$. $(5,6)$ The type strain of serovar yunnanensis. $(7,8)$ The soil isolate 97-OK-13-7. $(9,10)$ The soil isolate 01-KDT-118-10. $(11,12)$ The phylloplane isolate B52. 
thuringiensis strains produce proteinaceous crystalline parasporal inclusions in spore-forming cells. However, this is not the case with the type strain of B. thuringiensis serovar yunnanensis (H20ab) whose crystalline inclusions are formed in asporogenous cells but not in spore-forming cells (Ohba and Aizawa, 1986a; Srinivas et al., 1997). It appeared from the present results that, like the type strain, all 14 yunnanensis strains derived from natural environments in Japan produce large crystalline inclusions in spore-lacking cells but not in sporogenous cells.

Electron microscopic observations revealed that the inclusion matrix of the four selected strains (the type strain and the three Japanese isolates) consists of homogeneous electron-dense substances. Recently, Balasubramanian et al. (2002) reported that the cry32Aa gene is responsible for the production of crystal proteins in the type strain of yunnanensis. Thus, it is very likely that the electron-dense inclusion matrix observed here in the type strain is composed of the Cry32Aa protein.

Interestingly, Balasubramanian et al. (2002) reported that weak larvicidal activity against the diamondback moth, Plutella xylostella, was associated with the Cry32Aa protein expressed in Escherichia coli transformants. Our previous studies, however, have demonstrated that the mixtures of spores and inclusions of the yunnanensis strains, including the type strain, induced no significant mortality in larvae of the diamondback moth, even at high bacterial concentrations (Mizuki et al., 1999a; Higuchi et al., 2000; Ohba, unpublished observations). It is likely that low-levels of inclusion-forming cells ( $<1 \%$ of the cell populations), coupled with the low toxicity of inclusion proteins, may lead to a failure to detect insecticidal activity of the spore/ inclusion mixtures. Previous investigators have also reported that sporulated cultures of the existing yunnanensis strains gave no significant mortalities to other lepidopterans and dipterans tested (Wang et al., 1979; Ohba, 1996; Saitoh et al., 1996, 1998; Mizuki et al., 1999a; Higuchi et al., 2000; Ohba et al., 2000, 2002) and a coleopteran (Tsuchiya et al., 2002).

It is noteworthy that the yunnanensis strains tested also produced small round bodies in both spore-forming and asporogenous cells. Apparently, these bodies were different in many aspects from crystalline inclusions. Nickerson et al. (1981) made an interesting observation that the $B$. thuringiensis strain HD-1 (H3abc, serovar kurstaki) produced not only proteinaceous crystalline inclusions but also smaller spherical parasporal bodies (microscopically, phase-dark granules), consisting of poly- $\beta$ hydroxybutyrate (PHB). This leads to a hypothesis that the small round bodies present in the yunnanensis cells are composed of PHB. Chemical composition of these round bodies awaits clarification.

Our findings strongly suggest that the formation of crystalline inclusions in asporogenous cells is a prominent phenotypic character specifically associated with the H-serotype $20 \mathrm{ab}$ of $B$. thuringiensis. Our future works will include: (1) identification of cry genes in Japanese isolates of yunnanensis, (2) determination of whether insect toxicity and/or other biological activities are associated with the yunnanensis Cry proteins, and (3) comparative characterization of the crystalliferous yunnanensis strains and acrystalliferous Bacillus cereus isolates possessing the flagellar antigen $\mathrm{H} 20 \mathrm{ab}$ (Ohba and Aizawa, 1986b; Shisa et al., 2002).

\section{REFERENCES}

Akao, T., E. Mizuki, S. Yamashita, H. Saitoh and M. Ohba (1999) Lectin activity of Bacillus thuringiensis parasporal inclusion proteins. FEMS Microbiol. Lett. 179: 415-421.

Balasubramanian, P., R. Jayakumar, P. Shambharkar, N. Unnamalai, S. K. Pandian, N. S. Kumaraswami, R. Hangovan and V. Sekar (2002) Cloning and characterization of the crystal protein-encoding gene of Bacillus thuringiensis subsp. yunnanensis. Appl. Environ. Microbiol. 68: 408-411.

Glare, T. R. and M. O'Callaghan (2000) Bacillus thuringiensis: Biology, Ecology and Safety. Wiley, Chichester. 350 pp.

Higuchi, K., H. Saitoh, E. Mizuki, T. Ichimatsu and M. Ohba (2000) Larval susceptibility of the diamondback moth, Plutella xylostella (Lepidoptera: Plutellidae), to Bacillus thuringiensis $\mathrm{H}$ serovars isolated in Japan. Microbiol. Res. 155: 23-29.

Kondo, S., E. Mizuki, T. Akao and M. Ohba (2002) Antitrichomonal strains of Bacillus thuringiensis. Parasitol. Res. 88: 1090-1092.

Lecadet, M.-M., E. Frachon, V. Cosmao-Dumanoir, H. Ripouteau, S. Hamon, P. Laurent and I. Thiéry (1999) Updating the $\mathrm{H}$ antigen classification of Bacillus thuringiensis. J. Appl. Microbiol. 86: 660-672.

Mizuki, E., T. Ichimatsu, S.-H. Hwang, Y. S. Park, H. Saitoh, K. Higuchi and M. Ohba (1999a) Ubiquity of Bacillus thuringiensis on phylloplanes of arboreous and herbaceous plants in Japan. J. Appl. Microbiol. 86: 979-984.

Mizuki, E., M. Ohba, T. Akao, S. Yamashita, H. Saitoh and Y. S. Park (1999b) Unique activity associated with non-in- 
secticidal Bacillus thuringiensis parasporal inclusions: in vitro cell-killing action on human cancer cells. J. Appl. Microbiol. 86: 477-486.

Mizuki, E., Y. S. Park, H. Saitoh, S. Yamashita, T. Akao, K. Higuchi and M. Ohba (2000) Parasporin, a human leukemic cell-recognizing parasporal protein of Bacillus thuringiensis. Clin. Diagn. Lab. Immunol. 7: 625-634.

Nickerson, K. W., W. J. Zarnick and V. C. Kramer (1981) Poly- $\beta$-hydroxybutyrate bodies in Bacillus thuringiensis. FEMS Microbiol. Lett. 12: 327-331.

Ohba, M. (1996) Bacillus thuringiensis populations naturally occurring on mulberry leaves: a possible source of the populations associated with silkworm-rearing insectaries. J. Appl. Microbiol. 80: 56-64.

Ohba, M. and K. Aizawa (1986a) Crystals of Bacillus thuringiensis subsp. yunnanensis are produced only in asporogenous cells. J. Invertebr. Pathol. 48: 254-256.

Ohba, M. and K. Aizawa (1986b) Frequency of acrystalliferous spore-forming bacteria possessing flagellar antigens of Bacillus thuringiensis. J. Basic Microbiol. 26: $185-188$.

Ohba, M., A. Tsuchiyama, N. Shisa, K. Nakashima, D.-H. Lee, A. Ohgushi and N. Wasano (2002) Naturally occurring Bacillus thuringiensis in oceanic islands of Japan, Daito-shoto and Ogasawara-shoto. Appl. Entomol. Zool. 37: 477-480.

Ohba, M., N. Wasano and E. Mizuki (2000) Bacillus thuringiensis soil populations naturally occurring in the Ryukyus, a subtropic region of Japan. Microbiol. Res. 155: 17-22.
Saitoh, H., K. Higuchi, E. Mizuki and M. Ohba (1996) Larvicidal activity of Bacillus thuringiensis natural isolates, indigenous to Japan, against two nematoceran insect pests occurring in urban sewage environments. Microbiol. Res. 151: 263-271.

Saitoh, H., K. Higuchi, E. Mizuki and M. Ohba (1998) Larvicidal toxicity of Japanese Bacillus thuringiensis against the mosquito Anopheles stephensi. Med. Vet. Entomol. 12: $98-102$.

Shisa, N., N. Wasano, A. Ohgushi, D.-H. Lee and M. Ohba (2002) Extremely high frequency of common flagellar antigens between Bacillus thuringiensis and Bacillus cereus. FEMS Microbiol. Lett. 213: 93-96.

Srinivas, G., S. J. Vennison, S. N. Sudha, P. Balasubramanian and V. Sekar (1997) Unique regulation of crystal protein production in Bacillus thuringiensis subsp. yunnanensis is mediated by the Cry protein-encoding 103megadalton plasmid. Appl. Environ. Microbiol. 63: 2792-2797.

Tsuchiya, S., Y. Kasaishi, H. Harada, T. Ichimatsu, H. Saitoh, E. Mizuki and M. Ohba (2002) Assessment of the efficacy of Japanese Bacillus thuringiensis isolates against the cigarette beetle, Lasioderma serricorne (Coleoptera: Anobiidae). J. Invertebr. Pathol. 81: 122-126.

Wang, W., Q. Wang, X. Zhang and Y. Chen (1979) A new variety of Bacillus thuringiensis: B. thuringiensis var. yunnanensis. Acta Microbiol. Sin. 19: 117-121.

Yu, Z., J. Dai, H. Zhou, Z. Dong and W. Wang (1984) A new serotype of Bacillus thuringiensis. Acta Microbiol. Sin. 24: $117-121$. 